\title{
HEXSIL TWEEZERS WITH PIEZORESISTIVE POLYSILICON STRAIN GAGES
}

\author{
Chris G. Keller* and Roger T. Howe
}

Berkeley Sensor \& Actuator Center

\begin{abstract}
Depts. of *Materials Science and Mineral Engineering and \# Electrical Engineering and Computer Sciences University of Califomia at Berkeley, Berkeley, Califomia 94720-1774
\end{abstract}

\begin{abstract}
High aspect ratio molded polysilicon (hexsil) tweezers with an integrated phosphorus doped thermal expansion actuator beam and piezoresistive polysilicon strain gages for tactile feedback are described. The tweezers are normally closed, and require $75 \mathrm{~mW}$ to open $50 \mu \mathrm{m}$. Piezoresistor performance remains to be measured. The tweezer tips and flexible electrical interconnects between rotating beams are surface micromachined polysilicon.

\section{INTRODUCTION}

Tweezers with integrated actuators and force sensors are essential for automated assembly of systerns made up of independently microfabricated parts. The tweezers provide a mechanical interface between the macro and micro world: one end is macroscopic and can be coupled to conventional positioning actuators, while the other end is microscopic and can address small parts (e.g., $2 \mu \mathrm{m}$ to $100 \mu \mathrm{m}$ ) with the appropriate forces of a few $\mu$ Newtons.

The new features demonstrated here are (1) an integrated insitu phosphorous doped polysilicon thermal expansion actuator that is maintained in tension (the previous design [1] operated in compression), (2) surface polysilicon flexures (Fig. 1) to support metal lines that carry signals from one rotating hexsil beam to the next, (3) surface polysilicon tips with piezoresistive boron implanted polysilicon resistors to measure gripping force (in-plane bending) and to detect contact with the table top (out-of-plane bending), (4) a full Wheatstone bridge on a semicircular flexure (Fig. 2) to sense tweezer tip position when no object is being gripped, (5) an efficient 4bar linkage design with 30 to 1 leverage that amplifies the small motion of thermal expansion, (6) $100 \mu \mathrm{m}$ long hexsil flexures at each pivot point to provide low in-plane stiffness.
\end{abstract}

\section{THEORY}

Fig. 3 shows the $8 \mathrm{~mm}$ long by $1.5 \mathrm{~mm}$ wide hexsil [1-3] tweezers in the open (power on) position. In use, the base of the tweezer is bonded to a $2 \mathrm{~mm}$-wide, $5 \mathrm{~cm}$-long bar that mounts into a 3-axis micrometer drive positioner on a probe station.

The thermal expansion element (light gray) is electrically isolated from the rest of the device. Current travels up one leg and down the other. The beam heats up and lengthens, causing the other beams in the two 4 bar linkages to rotate and open the tweezer tips. Thermal actuation has the advantages of simple fabrication and no sliding contacts which would be vulnerable to failure due to wear or contamination. The beam was made as long as possible $(6 \mathrm{~mm})$ to minimize the operating temperature for a given displacement.

The design stress in the hexsil flexures is compressive and less than $1 \mathrm{MPa}$, while the thermal expansion element is maintained under a tensile stress of less than $0.1 \mathrm{MPa}$. The yield stress of polysilicon exceeds $1 \mathrm{GPa}$, and it is expected that the structures will operate indefinitely.

Boron implanted polysilicon piezoresistors are used in a 1/4 bridge configuration at each tweezer tip, and a full Wheatstone bridge is fabricated on the semicircular flexure closest to the tips. The tip gages are located along one edge of the surface polysilicon

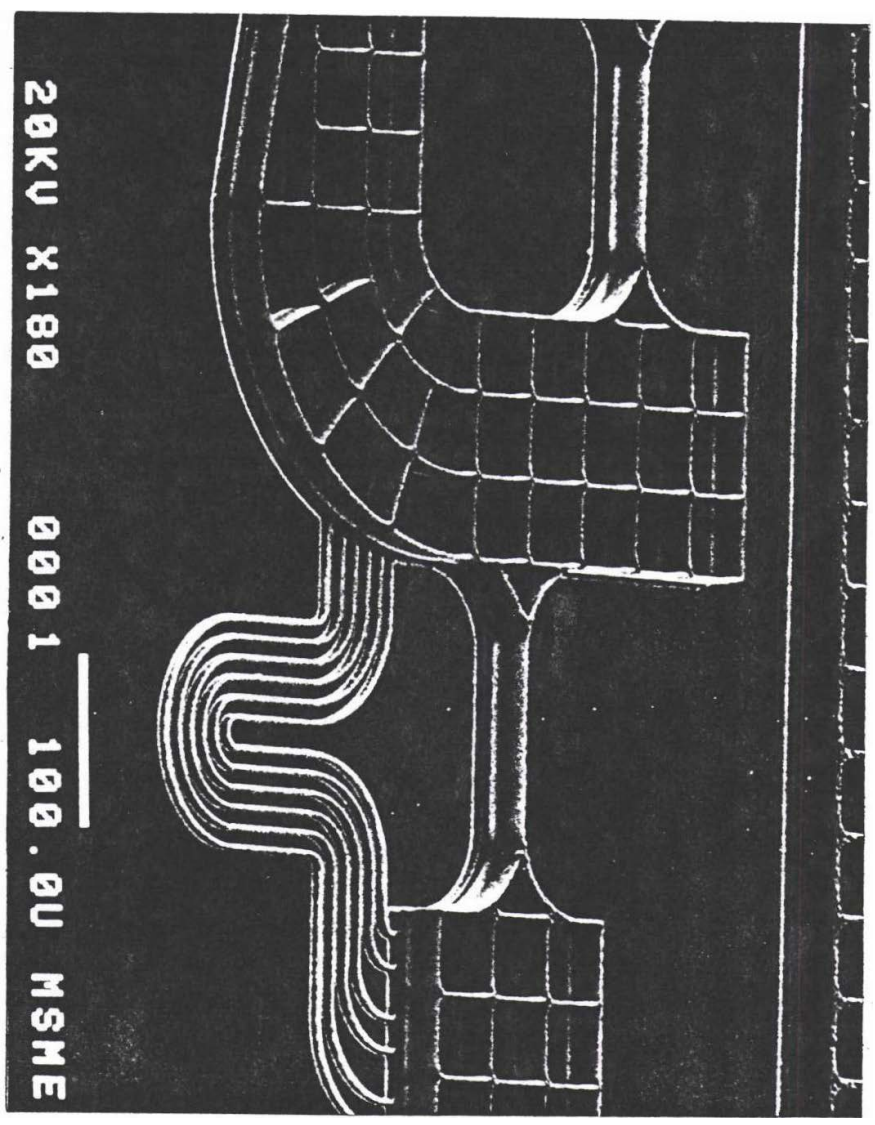

Figure 1. Surface poly flexures support metal lines between rotating hexsil beams; $100 \mu \mathrm{m}$ long hexsil flexures allow in-plane rotation.

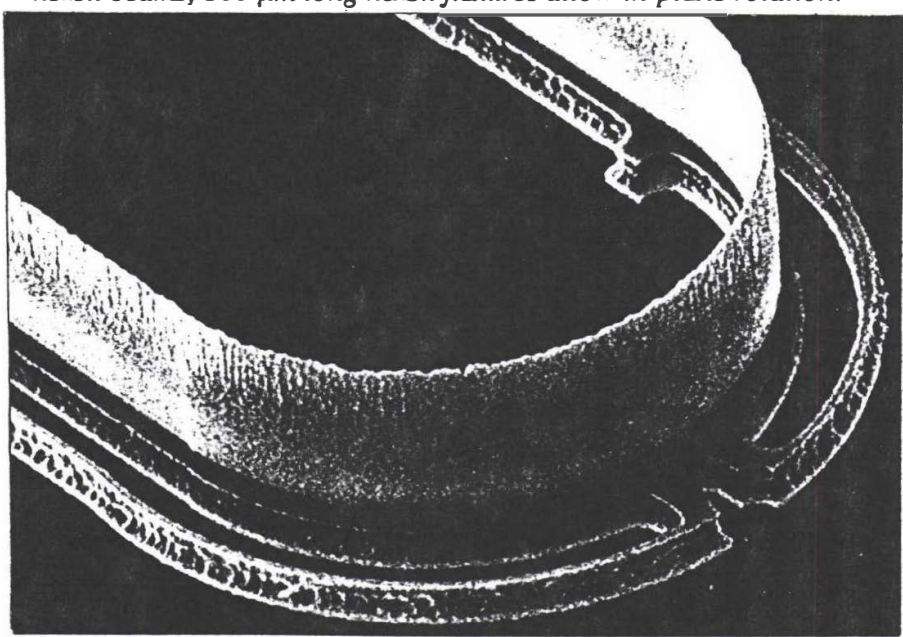

Figure 2. Bottom view of semicircular molded flexure with full Wheatstone bridge strain gage to sense tweezer tip position 
beam (Fig.4) so that they are in tension when an object is being gripped. Compression in these gages indicates contact with an object in front of the tweezers. If they are being lowered, tension indicates contact with the table top. Figure 5 shows a side-view schematic of the stiffness transition from the 500 $\mu \mathrm{m}$ thick handle (B) to the $40 \mu \mathrm{m}$ thick hexsil $(\mathrm{H})$ to the $5 \mu \mathrm{m}$-thick surface polysilicon tips $(\mathrm{S})$ to pick up an object $(P)$. The tips are also shown in plan view. The set point for the closed position depends on the width of the object to be picked up. There should be just enough bending strain in the tips to hold the object against gravity, but not so much that they become unstable to out-of-plane bending (in which case one tip bends up, one bends down, and the object flips out of the grip, never to be seen again). To prevent this, power to the actuator would be servoed on the strain gage signal. Care should be taken to avoid electrostatic fields and sticky adsorbed organic films which over power gravity.

\section{EXPERIMENTAL DETAILS}

After the tweezers are released from the mold, the rigid base is picked up with ordinary hand held steel tweezers and put on a $1.5 \mathrm{~mm} \times 0.5 \mathrm{~mm} \times 0.02 \mathrm{~mm}$ spot of epoxy at the end of a $5 \mathrm{~cm}$ bar. A tungsten probe tip is used to pull the expansion beam 1 to $2 \mu \mathrm{m}$ towards the base to close the tips, after which the beam is fixed to the base with a $100 \mu \mathrm{m}$ diameter drop of epoxy. After the epoxy cures, the tungsten probe is removed. After assembly, all the slender flexures are in compression (but not enough to cause buckling) and the only tensile member is the actuator beam, which has a large cross sectional area so the tensile stress is low. Wires are epoxied to the $5 \mathrm{~cm}$ bar and positioned to contact the ends of the thermal expansion beam, and the 12 terminal pads for the strain gages. Electrical contact is made by applying a tiny drop of silver paint with a tungsten probe tip.

Although the tweezers are intended to operate with the thermal beam in tension, it is found that the 4 bar linkages are sufficiently compliant that the thermal beam can also operate in compression with out buckling. This allows the tips to be opened wider than their as-molded position.

Tip deflections of about $50 \mu \mathrm{m}$ occur within less than $0.5 \mathrm{sec}$ with $75 \mathrm{~mW}$ dissipated in the expansion beam. The body of the tweezer is $40 \mu \mathrm{m}$-high, $2-\mu \mathrm{m}$ thick honeycomb cell walls (aspect ratio of 20:1). The strain gages are $0.4 \mu \mathrm{m}$ thick and implanted with boron $\left(5 \times 10^{15} / \mathrm{cm}^{2}\right.$ at $\left.30 \mathrm{keV}\right)$.

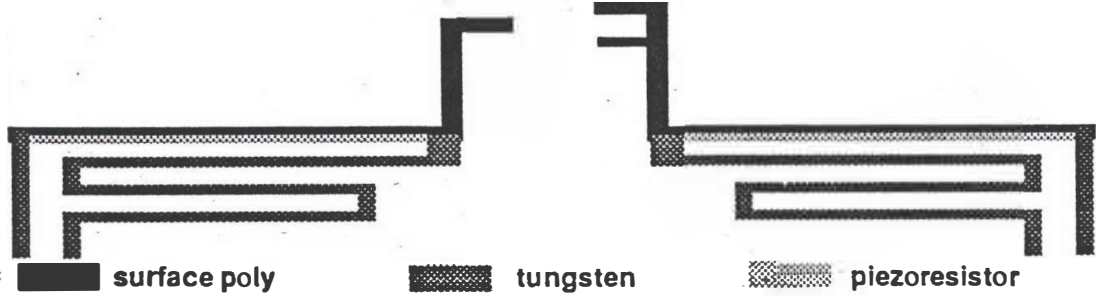

Figure 4. Surface polysilicon tweezer tips with piezoresistors

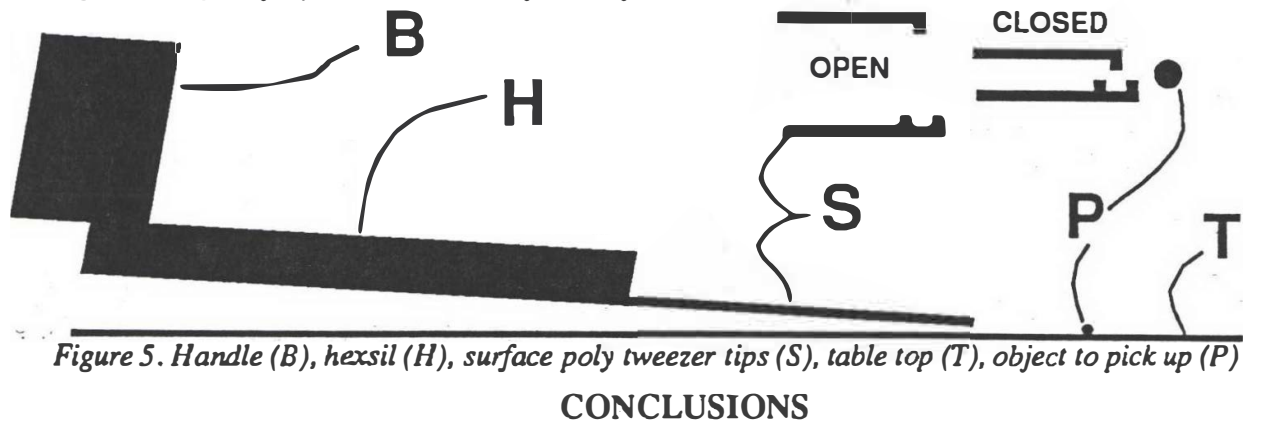

Closed-loop operation of the tweezers remains to be demonstrated. Using molded polysilicon fabrication technology, a microactuator designer has access to a versatile tool set that will evolve into an infrastructure for the routine and convenient manipulation of microfabricated parts.

\section{REFERENCES}

1. C. G. Keller and R. T. Howe, "Nickel-Filled Hexsil Thermally Actuated Tweezers", Transducers 95. The 8th Intemational Conference on Solid-State Sensors and Actuators, Stockholm, Sweden, June 1995, Vol. 2, pp. 376-379

2. C. G. Keller and R. T. Howe, "Hexsil Bimorphs for Vertical Actuation", Transducers 95, The 8th International Conference on Solid-State Sensors and Actuators, June 1995, Stockholm, Sweden, Vol. 1, pp. 99-102

3. C. G. Keller and M. Ferrari, "Milli-Scale Polysilicon Structures",1994 Solid State Sensor and Actuator Workshop, Hilton Head, S.C., June 1994, pp 132-137

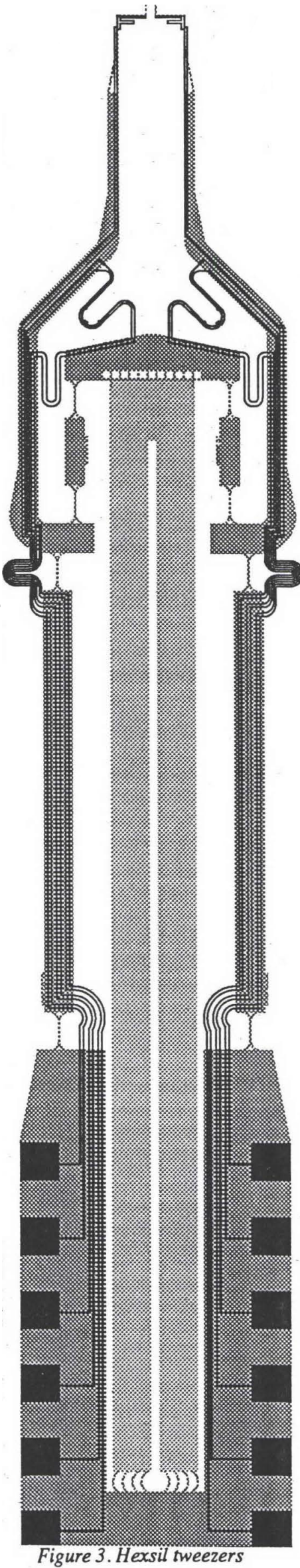

Figure 3. Hexsil tweezers 